\title{
Evaluation of energy absorbing materials under blast loading
}

\author{
H. Bornstein \& K. Ackland \\ Defence Science and Technology Organisation, Melbourne, Australia
}

\begin{abstract}
Traditional blast protection systems present a hard metallic surface, which acts to deflect and attenuate the blast loading. However, more recently, lightweight energy absorbing materials, including cellular materials, are being considered. These materials reduce the transmitted force by deforming elastically or plastically under the blast load. In this study, four commercially available energy absorbing materials were considered for application in blast protection. The materials considered were aluminium foam, Nomex ${ }^{\circledR}$ honeycomb, Skydex ${ }^{\circledR}$ and expanded polystyrene. The impulse transmitted by the rear face of experimental test panels under blast loading was assessed by positioning a mass on the rear face of each of the four panels, the velocity of which was measured using high speed imaging. Measurements of the permanent deformation of the rear face of the panels were also taken. The aluminium foam recorded both the lowest permanent deformation and impulse transfer to the mass of the materials tested, making it the most suitable material of those tested for use as an appliqué panel in this particular scenario. Analysis of the panels suggested that for the particular experimental setup used, minimal energy was absorbed by plastic deformation or crushing of the energy absorbing materials. Instead, the permanent deformation of the panels may be related to the mechanical properties of the materials in the plane perpendicular to the blast load.
\end{abstract}

Keywords: energy absorbing materials, blast, blast testing.

\section{Introduction}

Energy absorbing materials have been investigated for a variety of different applications when subjected to blast and impact loading. Metallic and nonmetallic foams and honeycombs are designed to crush under loading, thus 
absorbing energy and reducing the load transfer to the primary structure behind them. These materials or structures are generally characterised by their compressive stress-strain curves, which typically show an initial elastic region, followed by a plateau stress representing plastic yielding (Figure 1). Densification occurs when the material has been significantly compressed and is identified by a sharp rise in stress.

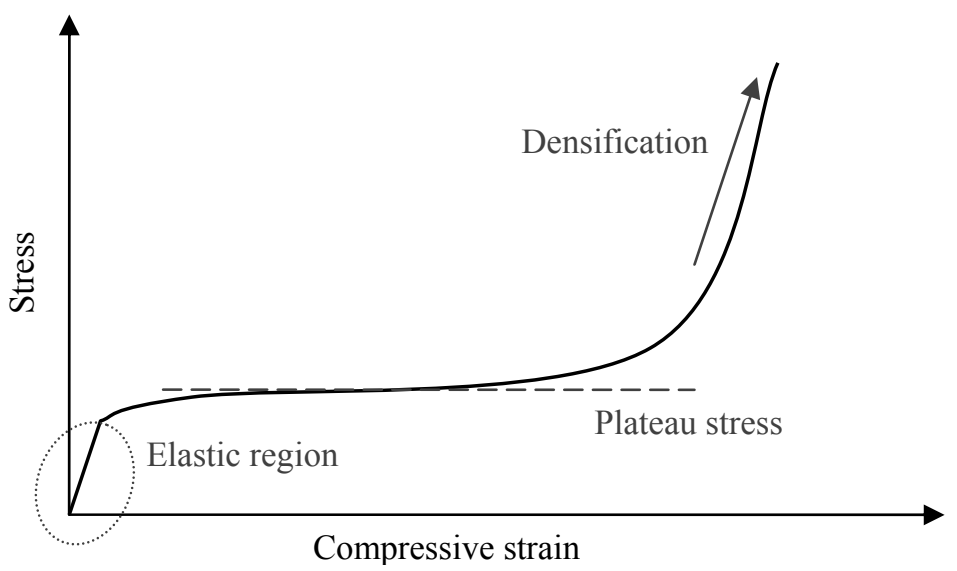

Figure 1: Typical shape of a stress-strain curve of a crushable energy absorbing material or structure.

Karagiozova et al. [1] investigated the properties of aluminium honeycomb and polystyrene sandwich panels subjected to near-field blast loading using both experimental testing and numerical modelling. They showed that as the loading increases, the densification of the foam can result in high force transmissions to the back faces of sandwich panels. This suggests that energy absorbing materials can only be optimised for a particular loading and may not provide good performance once overmatched. They also found that the force transmitted to the back face of the sandwich panels increased with density for thinner panels. This assessment is also supported by Zhu [2], who compared a range of aluminium honeycomb and aluminium foams. For thicker panels, the force transmitted was related to the core efficiency (the ratio between the energy absorbed per unit mass of the core and the density of the core). This leads to the suggestion that lighter materials with high plateau stresses might be the best core materials, when it is feasible to use a thick core.

Zhu [2] also performed an analytical study into the deformation of the panels, which relied on a simplifying assumption that divides the structural response of the panel into three distinct loading phases. These are defined as follows:

1. The blast load is transmitted to the front face, which attains a given velocity, while the rest of the structure is stationary.

2. The core is compressed, while the back face remains stationary.

3. The back face begins to deform and the structure is brought to rest by plastic bending and stretching. 
As the structure is brought to rest by bending and stretching, the permanent deformation of a sandwich panel is likely to be affected by the compressive and shear strength and moduli in the planes perpendicular to the loading direction of the core material in addition to its properties under axial compression.

Other studies investigating the use of energy absorbing materials under blast loading include Warne et al. [3] and Hanssen et al. [4]. Warne et al. compared the permanent deformation of the rear face of sandwich panels under blast loading using expanded polystyrene, polyethylene 30 , Nomex ${ }^{\circledR}$ honeycomb and a bare steel panel. It was found that the Nomex $^{\circledR}$ honeycomb provided the best performance in terms of back face deformation. Hanssen et al. investigated the use of aluminium foam panels attached to a pendulum and subjected to near-field blast loading. They found that the addition of the aluminium foam panel resulted in an increase in the impulse delivered to the pendulum, although the authors were not able to provide a definitive reason for this. They also conducted an analytical study, which showed that whilst the peak force was reduced by the panels, the loading duration increased, suggesting that whilst foam panels can control the peak stresses they cannot reduce the momentum transfer to a structure.

The use of energy absorbing materials is not limited in application to protecting structures from blast loading, but is also used to protect personnel. Wang et al. [5] investigated the use of Nomex ${ }^{\circledR}$ honeycomb and aluminium honeycomb for use in landmine resistant boots. They observed that whilst both provided a reduction in the transmitted force, the Nomex ${ }^{\circledR}$ honeycomb, which had a lower plateau stress, provided better performance. Wang et al. [6] compared the use of Nomex ${ }^{\circledR}$ honeycomb and polystyrene for the use in false floors in armoured vehicles to protect against lower limb injuries during landmine loading. It was observed under drop testing conditions that the Nomex ${ }^{\circledR}$ honeycomb provided slightly better performance than the polystyrene. Work by McKay [7] compared a range of aluminium honeycomb materials and aluminium foam for use in false floors. His research showed that the plateau stress of a material must be tuned to be just below the threshold for lower leg injury to minimise the risk of lower leg injury. The plateau stress of the Nomex ${ }^{\circledR}$ honeycomb tested by Wang et al. was very similar to the best performing aluminium honeycomb tested by McKay. It should be noted that these tests subjected the panel to axial compressive loads only.

This paper investigates the performance of four different commercially available energy absorbing materials in the role of an appliqué panel to be placed on a structure. The comparison between the materials is performed by analysing the impulse transmitted by the back face of sandwich panels under blast loading as well as the deformation of the rear structure. The study was conducted using an experimental blast test.

\section{Experimental method}

An experiment was designed and conducted around the use of four commercially available energy absorbing materials. The materials selected for comparison 
were Nomex ${ }^{\circledR}$ honeycomb, Skydex ${ }^{\circledR}$ convoy decking, Alporas aluminium foam and expanded polystyrene (EPS). The Skydex ${ }^{\circledR}$ convoy decking was selected as it is a commercially available energy absorbing foot pad used in US military vehicles such as the MRAP [8]. The selected materials are shown in Figure 2.
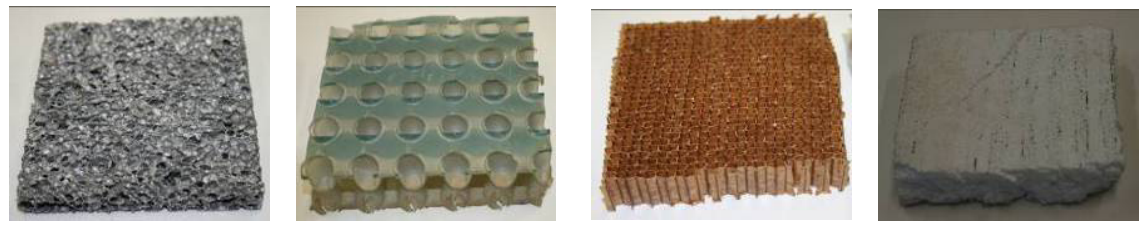

Figure 2: (Left to right) aluminium foam, Skydex ${ }^{\circledR}, \operatorname{Nomex}^{\circledR}$ honeycomb and EPS.

As there were limitations surrounding the availability of identical thicknesses of the four materials, the material thicknesses varied slightly. Table 1 provides the densities and thicknesses of the materials. The Skydex ${ }^{\circledR}$ came in the form of a double layer convoy deck, which was modified to a single layer without the top rubber layer for use in a sandwich panel. The stress-strain properties under uniaxial compression of the four materials are presented in Figure 3. The stressstrain curves for the aluminium foam, EPS and Nomex ${ }^{\circledR}$ were sourced from literature $[1,6,9]$, while the Skydex ${ }^{\circledR}$ curve was taken from information provided by the company [10] for the single layer convoy decking.

Table 1: Energy absorbing material densities, thicknesses and elastic moduli.

\begin{tabular}{|c|c|c|c|c|}
\hline Material & $\begin{array}{l}\text { Density } \\
\left(\mathrm{kg} / \mathrm{m}^{3}\right)\end{array}$ & $\begin{array}{c}\text { Thickness } \\
\text { (mm) }\end{array}$ & $\begin{array}{l}\text { Areal density } \\
\qquad\left(\mathrm{kg} / \mathrm{m}^{2}\right)\end{array}$ & $\begin{array}{c}\text { Elastic modulus } \\
\text { (GPa) }\end{array}$ \\
\hline $\begin{array}{l}\text { Aluminium } \\
\text { foam }\end{array}$ & 217 & 14 & 3.04 & 69 \\
\hline Skydex & 170 & 25 & 4.25 & 1.4 \\
\hline Nomex & 36 & 20 & 0.72 & 29 \\
\hline EPS & 28 & 22 & 0.62 & $<3$ \\
\hline
\end{tabular}

Sandwich panels were made for each material with a $500 \mathrm{~mm} \times 500 \mathrm{~mm}$ $\times 1.7 \mathrm{~mm}$ steel panel as the front face, a $500 \mathrm{~mm} \times 500 \mathrm{~mm}$ energy absorbing layer, and a $600 \mathrm{~mm} \times 600 \mathrm{~mm} \times 1.7 \mathrm{~mm}$ steel panel as the back face. Sikaflex ${ }^{B}$ 291 was used to bond the materials to make the sandwich panels. The structure of the panels is shown in Figure 4, together with a schematic of the test layout. 


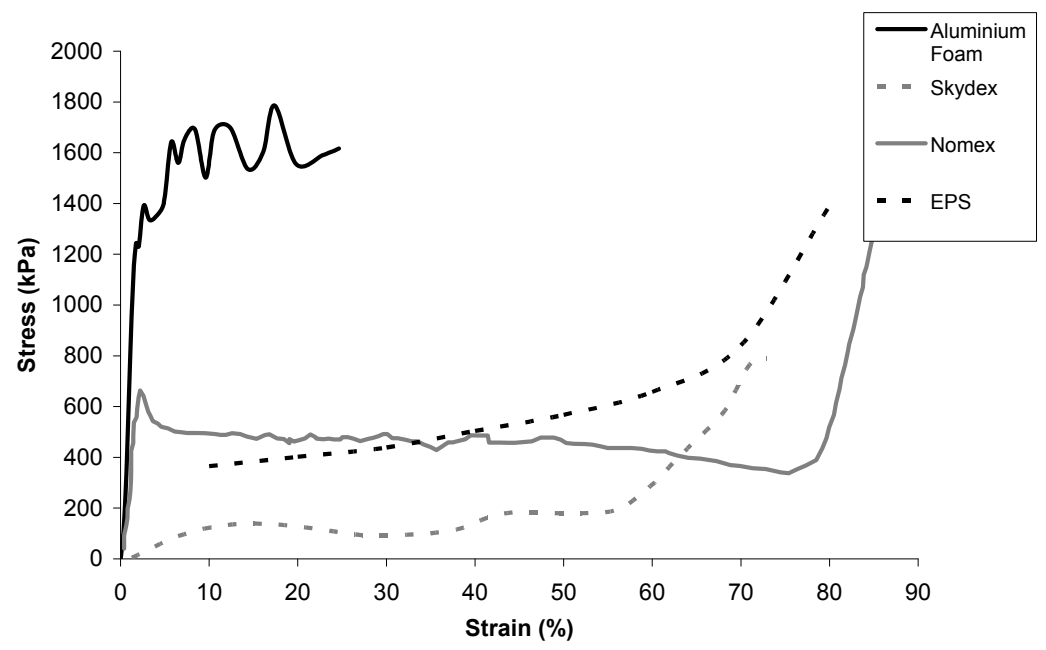

Figure 3: $\quad$ Stress-strain properties of materials under uniaxial compression (as obtained from the literature).

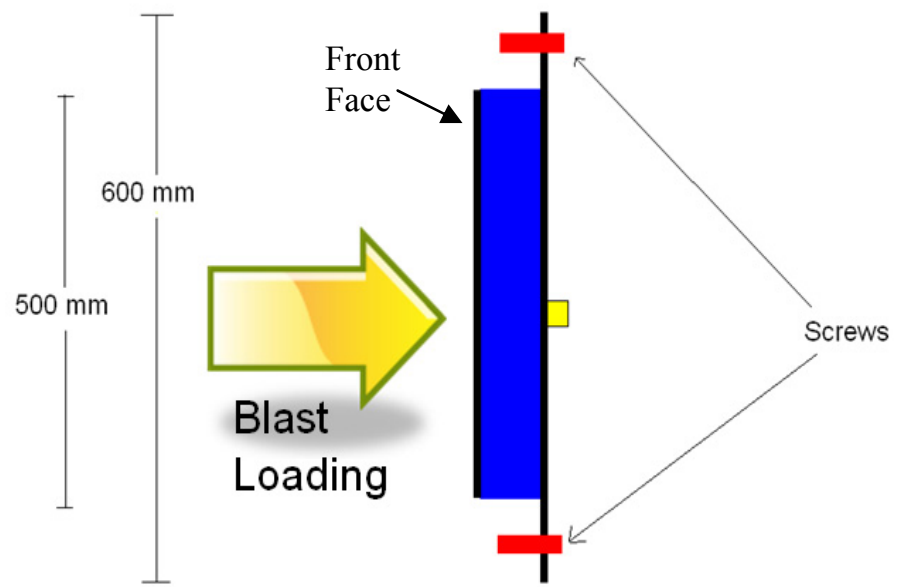

Figure 4: $\quad$ Schematic of sandwich panel setup for experiments.

The rear face of each sandwich panel was then attached to the target stand using 16 evenly spaced screws to represent a structure with an energy absorbing appliqué. The setup of the sandwich panels on the target stand is shown in Figure 5. A $12.8 \mathrm{~kg}$ cubic PE4 charge was placed on a stand with the centre of the charge $500 \mathrm{~mm}$ above the ground. The target stand was positioned such that the centre of the stand was $5 \mathrm{~m}$ from the charge centre and was perpendicular to the face of the charge. This distance was selected as it is on the edge of the fireball for this charge size and hence would allow high-speed video to record the back face of the panels. 


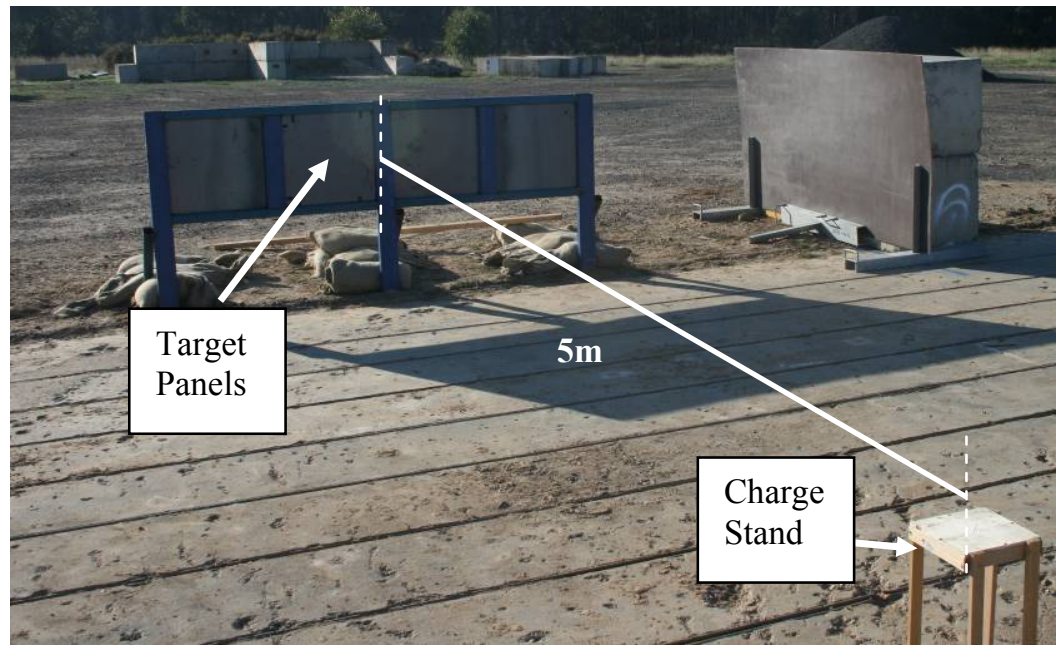

Figure 5: $\quad$ Setup of target panels and explosive charge.

A nail was glued in position at the centre of the rear face of each sandwich panel. This allowed an aluminium cylinder to be mounted flush with the rear surface of the plate. The aluminium cylinders were $30 \mathrm{~mm}$ in diameter and $20 \mathrm{~mm}$ in length. They were painted in bright colours for identification on the high-speed video footage. The video was taken at 6000 frames per second to record the velocity of the cylinders. Images were taken with reference markers prior to the event for each panel to calibrate distances within the high-speed video footage. Figure 6 shows the rear face of the sandwich panels with the aluminium cylinders in position.

Traditionally the performance of sandwich panels is evaluated experimentally by using the permanent rear face deformation. The aluminium cylinders were used to provide a measurement of the impulse transmitted by the rear face of a sandwich panel to an object in direct contact with it. This measurement technique was used to determine whether there was any correlation between the load transfer to the rear face of the panel and the permanent rear face deformation.

Due to the cubic shape of the explosive charge and the shape of the target stand, there was some asymmetry between the loading on the inner (Skydex ${ }^{\circledR}$ and Nomex ${ }^{\circledR}$ honeycomb) and outer (EPS and aluminium foam) sandwich panels on the target fixture. However, preliminary simulations performed in AUTODYN predicted only a small difference $(\leq 5 \%)$ in the cylinder velocities for a bare steel panel at the inner and outer panel locations.

The residual deformation from each sandwich panel was measured using a 3D laser scanner. 


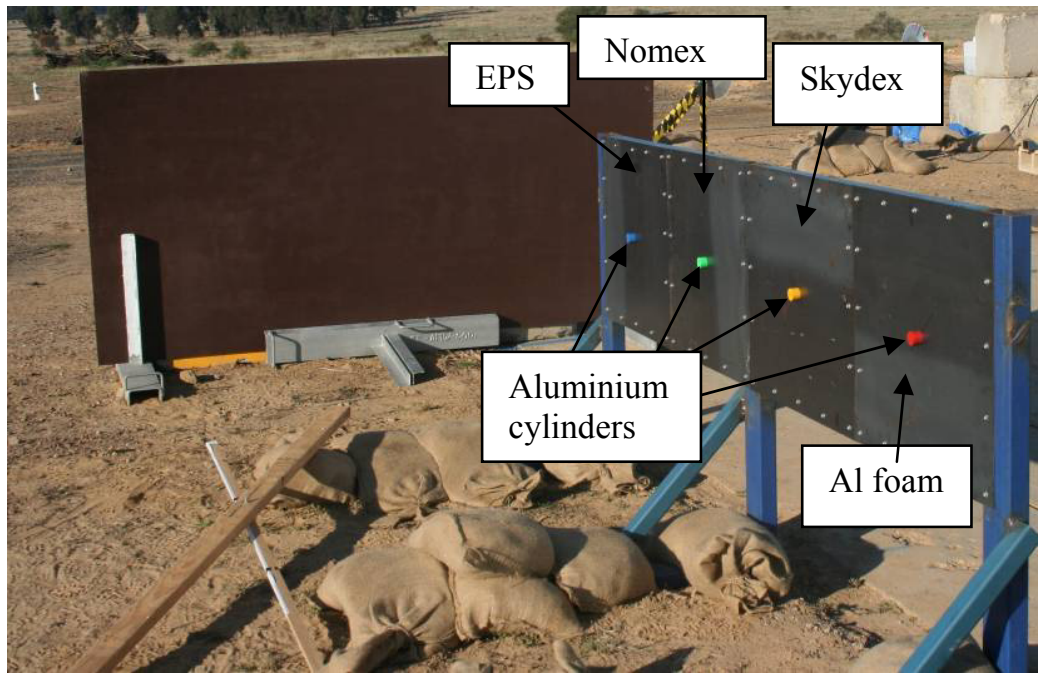

Figure 6: $\quad$ Rear face of sandwich panels.

\section{Experimental results}

The high-speed video footage was analysed to record the velocities of the aluminium cylinders for each of the panels. Unfortunately, due to limitations in the experimental design, the panels became dislodged during the event. This affected the boundary conditions of the experiment, and made it difficult to draw any firm conclusions based on the cylinder velocities. The velocities of the aluminium cylinders are presented in Figure 7. There appears to be two distinct acceleration phases on the curve, which could represent different loading mechanisms by the panels on the cylinders. The potential acceleration mechanisms are acceleration due to rear face deformation, global motion of the panel after failure of the boundary conditions, and load transmission through the panel due to the compressive stress wave propagation. Analysis of the highspeed video indicates that the first acceleration phase is due to rear face deformation. The high-speed video footage also shows that the aluminium foam panel breaks away from the target fixture at $\sim 4 \mathrm{~ms}$, which corresponds to the second acceleration phase of the aluminium cylinders (global motion of the panel after boundary failure). The average velocities of the aluminium cylinders were taken once the cylinder velocity had reached a plateau and are shown in Table 2. This plateau occurred after $\sim 6 \mathrm{~ms}$. Further analysis of the high-speed video indicates that the screws on all panels failed at a similar time. If the assumption is then made that the failure of the screws required minimal energy, then the impulse transmitted to the cylinders of all panels due to global motion of the panels should have been similar. Whilst definitive conclusions on the different materials performance based on the cylinder velocities cannot be drawn due to failure of the boundary conditions, the differences may still be indicative of their relative performance. 
The aluminium foam panel clearly had the lowest cylinder velocity. This could be attributed to its stiffness allowing minimal panel deformation to accelerate the cylinder in the initial acceleration phase.

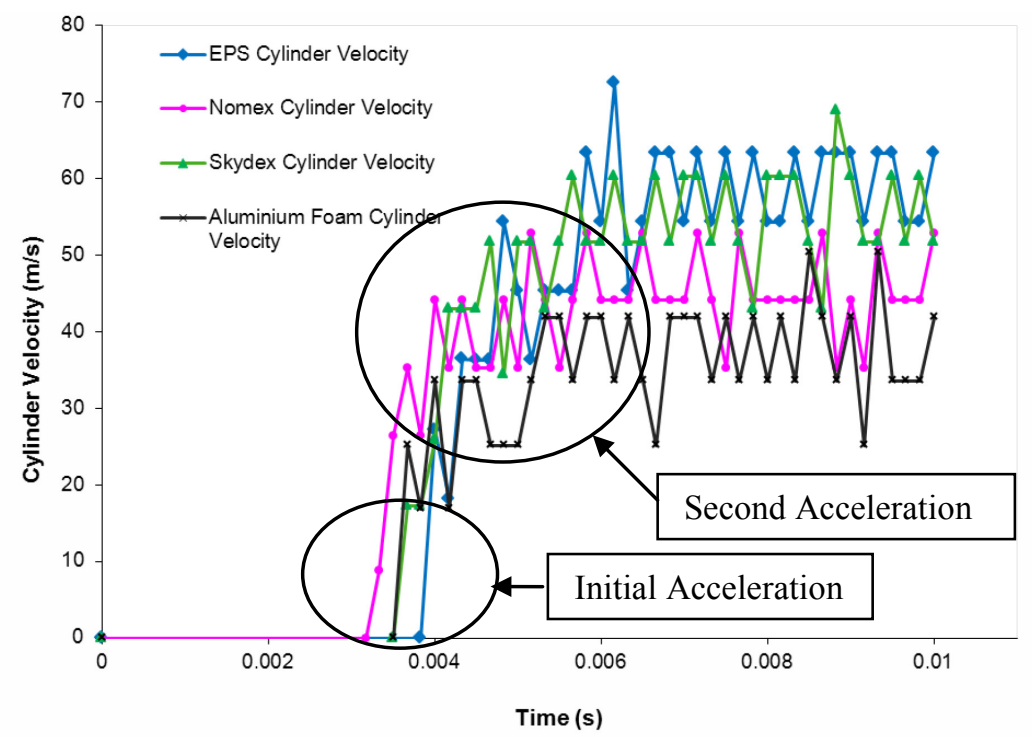

Figure 7: Aluminium cylinder velocity vs. time results.

Table 2: Aluminium cylinder velocity for energy absorbing material panels. The adjusted velocity adds an increase in velocity of $5 \%$ to allow for differences in loading due to panel location.

\begin{tabular}{|c|c|c|c|}
\hline Material & $\begin{array}{c}\text { Cylinder } \\
\text { Velocity (m/s) }\end{array}$ & $\begin{array}{c}\text { Panel } \\
\text { Location }\end{array}$ & $\begin{array}{c}\text { Adjusted velocity } \\
(\mathbf{m} / \mathbf{s})\end{array}$ \\
\hline Aluminium Foam & 35.2 & Outer & 37.0 \\
\hline Skydex $^{\circledR}$ & 50.5 & Inner & 50.5 \\
\hline Nomex $^{\circledR}$ honeycomb & 43.4 & Inner & 43.4 \\
\hline EPS & 54.8 & Outer & 57.5 \\
\hline
\end{tabular}

Figure 8 shows the rear faces of the four sandwich panels. The aluminium foam panel had almost no permanent deformation, although the high-speed video showed that there was elastic deformation of the panel. The Skydex ${ }^{\circledR}$ and EPS panels showed similar deformation profiles to those expected by a rectangular plate under blast loading. However, the Nomex ${ }^{\circledR}$ honeycomb panel is shown to have a different deformation profile to the Skydex ${ }^{\circledR}$ and EPS. Unlike the other materials, Nomex ${ }^{\circledR}$ honeycomb has different mechanical properties along each of its three axes [11, 12]. Preliminary testing by Hexcel composites [12] has shown that for the grade of Nomex ${ }^{\circledR}$ honeycomb used there is a $50 \%$ difference in the shear strength depending on the direction of the applied load. This anisotropy in 
the material appears to have resulted in the panel deforming preferentially in one plane. This indicated that the mechanical properties of the material in all axes are important in determining the deformation profile of the sandwich panel. Another possible contributing factor to the deformation profiles is the variation in boundary conditions between the panels due to the panels coming away from the target stand. However as all the panels were dislodged before they had finished their structural response, it is unlikely that the boundary conditions significantly affected the difference in deformation profiles seen between the panels.
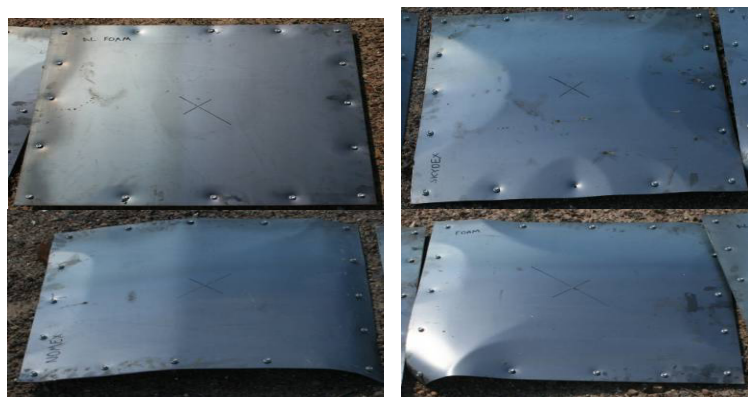

Figure 8: $\quad$ Rear faces of the sandwich panels; (top left) aluminium foam (top right) $S_{k y d e x}{ }^{\circledR}$ (bottom left) Nomex ${ }^{\mathbb{B}}$ honeycomb (bottom right) EPS.

The deformation profiles were analysed using a 3D laser scanner with the resulting deformations presented in Figure 9. These profiles were measured across the plate centres between the midpoints of two opposite edges. The Skydex ${ }^{\circledR}$ and EPS not only had similar deformation profiles but the magnitude of their deformation profiles was found to be very similar. Skydex ${ }^{\circledR}$ and EPS have a tendency to recover post event, hence negligible plastic deformation was observed in the materials after the event. It is likely that due to their low elastic modulus, both the Skydex and EPS absorbed some energy under compression during the event.

The Nomex ${ }^{\circledR}$ honeycomb panel recorded a larger permanent deformation than any of the other panels. Post event analysis of the Nomex ${ }^{\circledR}$ honeycomb also revealed that very little plastic deformation of the material had occurred. As mentioned previously, Nomex ${ }^{\circledR}$ honeycomb is largely anisotropic. The compressive strength and modulus of honeycomb structure in the directions perpendicular to the blast can be less than $5 \%$ of the through-thickness strength [12]. These properties make the Nomex ${ }^{\circledR}$ particularly susceptible to large deformations under bending loads.

The aluminium foam panel had the lowest permanent deformation and the foam was not found to have compressed during the event. This suggests that in this particular experiment, the benefit it provided in comparison to the other materials was its higher strength and moduli in all directions. This is shown by its higher compressive strength (see Figure 3) compared to the other materials in conjunction with its isotropic properties. 


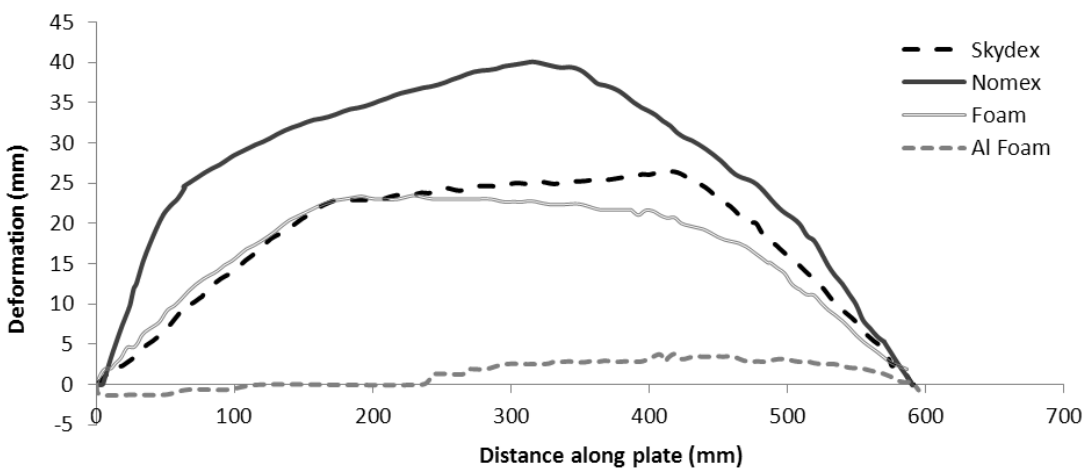

Figure 9: Deformation profiles of the rear faces of the sandwich panels. The Nomex ${ }^{\circledR}$ was assessed in the direction of maximum deformation.

None of the materials showed evidence of plastic deformation under the compressive loading. This may have been due to the rear panels deforming and coming away from the fixture before the materials were able to compress. Alternatively, as the panels were outside the fireball, the loading on the panels may not have been sufficient to cause compression of the materials.

\section{Discussion on the experimental design}

The experiment, even with the issues highlighted below, identified that the mechanical properties of the panels in the planes perpendicular to the blast direction are important when examining the permanent deformation of the rear face, as well as their properties in direction of the blast. As the intention of the experimental setup was to look at appliqué panels under conditions where large deformations were expected, materials selected in future work should have reasonable compressive and shear strength and moduli in all directions. Data on such materials is therefore required in both quasi-static and high strain rate regimes in multiple directions to assess their suitability for use as an appliqué. Materials such as Nomex ${ }^{\circledR}$ honeycomb may not be suitable for this type of application. It is also recognised that the rear face of the panel should be thicker than the front face of the panel to represent a more realistic appliqué armour scenario.

The intended use of the cylinder velocity was to record whether there was a correlation between the performance of different materials when comparing the load transferred through a panel and the permanent deformation of the panel. Whilst there appeared to be a difference, this observation was not conclusive due to the detachment of the panels from the supporting frame during the event. The results suggested that the cylinder velocity was generated by the initial velocity of the centre of the rear face of the panel, as well as the global velocity of the plate after detachment. The detachment of the panels at the boundaries could be 
rectified in future by an improved boundary design, which does not allow detachment.

A number of design improvements in the setup of the experiment would have to produce more meaningful analysis of the different core materials for sandwich panels under blast loading. The panels coming away from the target stand during the event provided a modification in boundary conditions that made meaningful analysis of the results difficult, especially the cylinder velocities. This could be rectified by mounting the rear face of the panels to the front of a heavier frame.

The experiment was conducted outside the fireball, which may have limited the blast loading to a level that did not allow compression of the energy absorbing materials. It is intended that future experiments focus on scenarios with smaller charges but in the near-field as is more frequently performed in the literature.

A number of materials were compared for their suitability as appliqué armour but there was no baseline test without an appliqué material. A baseline test would have allowed measurement of the improvement provided by each appliqué. If numerical modelling of the experiment was to be conducted it would also provide a suitable data point for validation of the applied loading conditions. Validating the experimental loading conditions in a numerical model with complex material properties such as the appliqués used here would present a much greater challenge.

\section{Conclusions}

The experimental results presented in this paper showed that the aluminium foam provided superior performance to the other materials tested in terms of use as an appliqué panel for these particular test conditions. It recorded both the lowest permanent deformation and impulse transfer to the cylinder of the materials tested. For the scenario evaluated, due to the minimal energy absorption via compression of the panels, it appeared that performance of the materials was governed by more than just the compressive stress-strain behaviour of the material. Evidence of the anisotropic effects of honeycomb materials was shown by the asymmetric deformation profile of the Nomex ${ }^{\circledR}$ panel. This is particularly important when looking at an appliqué panel for structures undergoing significant deformation as the core material of the sandwich panel will be subjected to significant bending forces. A number of experimental design improvements were found, most notably improvements to the panel boundary fixtures.

\section{Acknowledgements}

The authors would like to acknowledge the assistance of Steve Pattie, Frank Marian, Andrew McLean, Darren Wiese, Emily Frain and Chris Townsend and the staff at P\&EE Graytown for their assistance in setting up and conducting the blast trial. The authors would also like to thank Stuart Cannon, Leo de Yong, 
Craig Flockhart, Stephen Cimpoeru and Brian Dixon for their independent advice.

\section{References}

[1] Karagiozova, D., Nurick, G., Langdon, G., Chung Kim Yuen, S., Chi, Y. and Bartle, S., Response of flexible sandwich-type panels to blast loading, Composites Science and Technology, 69(6), pp. 754-763, 2009.

[2] Zhu, F., Impulsive loading off sandwich structures with cellular cores, $\mathrm{PhD}$ thesis, Swinburne University of Technology, 2008.

[3] Warne, S., Anderson, C. and Ackland, K., The use of energy absorbing materials within a blast scenario, 18th International Conference on Shock and Impact Loads on Structures, Adelaide, 2009.

[4] Hanssen, A., Enstock, L. and Langseth, M., Close-range blast loading of aluminium foam panels, International journal of impact engineering, 27, pp. 593-618, 2002.

[5] Wang, J., Bird, R., Swinton, B. and Krstic, A., Experimental and computational research for conceptual design of mine-resistant boots, Journal of battlefield technology, 6(1), 2003.

[6] Wang, J., Bird, R., Swinton, B. and Krstic, A., Protection of lower limbs against floor impact in army vehicles experiencing landmine explosion, Journal of battlefield technology, 4(3), 2001.

[7] McKay, B., Development Of lower extremity injury criteria and biomechanical surrogate to evaluate military vehicle occupant injury during an explosive blast event, Wayne state university dissertations, Paper 146, 2010.

[8] Skydex ${ }^{\circledR}$ applications, <http://www.skydex.com/technology/applications $>$, Accessed 31 May 2012.

[9] Danneman, K. and Lankford Jr, J., High strain rate compression of closedcell aluminium foams, Materials science and engineering, 293(1-2), pp. 157-164, 2000.

[10] Metzer, C., Personal communication, 23 February 2011, Skydex Technologies Inc.

[11] Foo, C., Chai, G. and Seah, L. Mechanical properties of Nomex material and Nomex honeycomb structure, Composite Structures, 80, pp. 588-594, 2007.

[12] Hexcel composites, HexWeb ${ }^{\mathrm{TM}}$ honeycomb attributes and properties, http://www.hexcel.com/Resources/DataSheets/Brochure-DataSheets/Honeycomb Attributes and Properties.pdf, accessed 10 July 2012. 